\title{
Giant pseudoaneurysm at the proximal vein graft anastomosis after Bentall procedure for Takayasu arteritis
}

\author{
Kenichi Hashizume, MD, Ryuichi Takahashi, MD, and Kouji Tsutsumi, MD
}

\begin{abstract}
A 39-year-old man with Takayasu arteritis underwent a modified Bentall procedure with a $28-\mathrm{mm}$ Hemashield tube graft (Hemashield Gold; Boston Scientific, Wayne, $\mathrm{NJ}$ ) and an ATS standard 25-mm valve (ATS Medical, Inc, Minneapolis, Minn) with additional aortocoronary bypass surgery 4 years ago because of suspected ischemia of the left anterior descending artery during weaning from cardiopulmonary bypass.

The patient recently experienced pectoralgia, and subsequent multidetector computed tomography revealed a rare anastomotic pseudoaneurysm that had formed gradually (Figure 1). This appeared as a giant pseudoaneurysm $70 \times$ $35 \mathrm{~mm}$ in diameter at the site of the saphenous vein bypass graft in front of the ascending aorta that had been replaced with the prosthetic graft. However, it was unclear whether the pseudoaneurysm was a proximal composite graft anastomosis or a coronary ostium anastomosis. There was no significant stenosis in the left anterior descending artery.
\end{abstract}

A corrective surgical procedure was performed through re-do median sternotomy after femorofemoral bypass because computed tomography confirmed that the pseudoaneurysm was not just under the sternum (Figure 2).

Oftentimes, such aneurysms are large enough to abut the posterior table of the sternum. In this case, one option was to place the patient under profound hypothermic circulatory arrest before sternotomy. Another option was to clamp the aorta, because it was understood that the pseudoaneurysm consisted of the coronary ostium anastomosis.

When the pseudoaneurysm was opened after the distal end of the composite graft was clamped and cardioplegia was given antegrade from the pseudoaneurysm, the

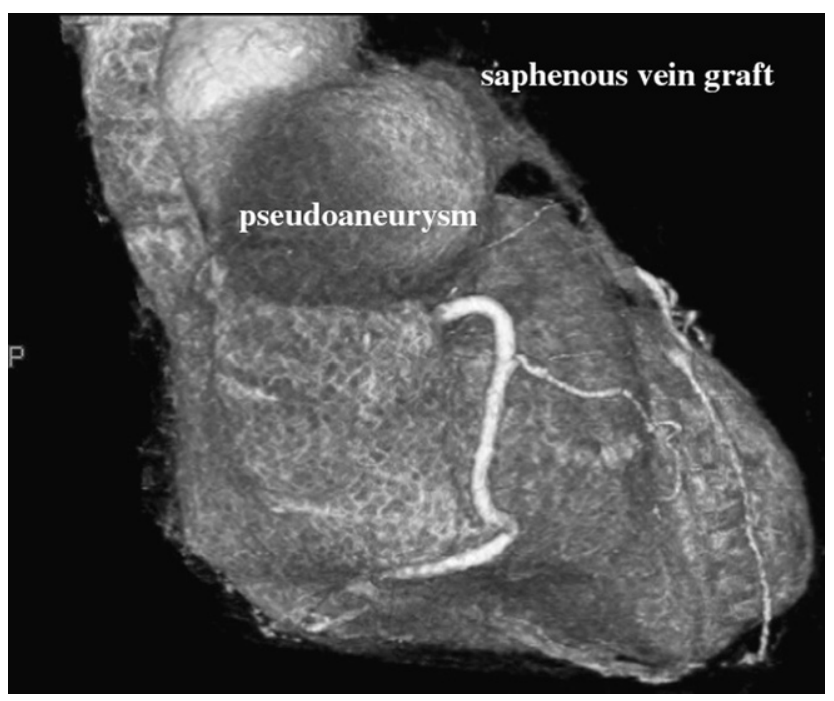

FIGURE 1. Multidetector computed tomography scan shows a giant pseudoaneurysm and the saphenous vein bypass graft in front of the ascending aorta that had been replaced with the prosthetic graft.

proximal end of the vein graft was found to have detached completely from the artificial aorta (Figure 3). To repair the pseudoaneurysm, we ligated the saphenous vein graft, which had been occluded, and closed the opening of the anastomosis of the vascular prosthesis.

We did not use profound hypothermia but approached the aneurysm with femorofemoral bypass and cardioplegic arrest alone in a less invasive manner. The patient's postoperative course was uneventful.

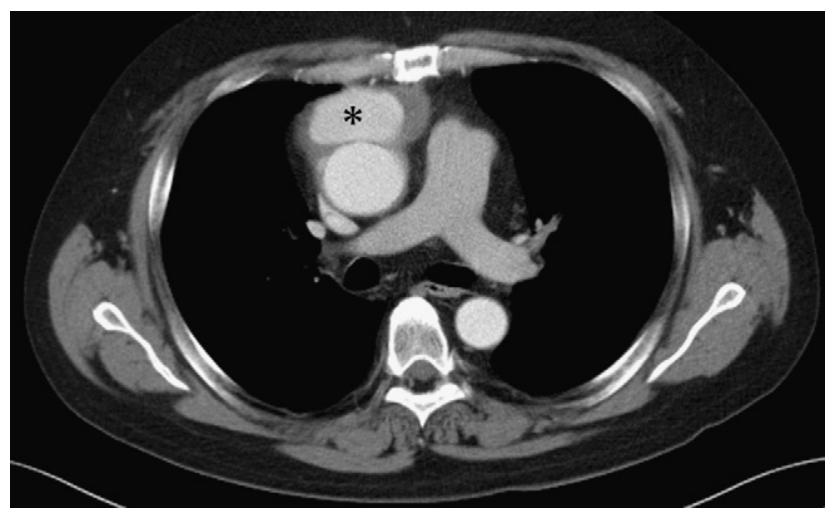

FIGURE 2. Computed tomography scan shows the pseudoaneurysm in front of the ascending aorta was not just under the sternum. *Pseudoaneurysm.

\footnotetext{
From the Department of Cardiovascular Surgery, Saiseikai Utsunomiya Hospital, Tochigi, Japan.

Disclosures: Authors have nothing to disclose with regard to commercial support.

Received for publication May 5, 2011; accepted for publication May 25, 2011; available ahead of print June 27, 2011.

Address for reprints: Kenichi Hashizume, MD, Department of Cardiovascular Surgery, Saiseikai Utsunomiya Hospital, Takebayashi 911-1, Utsunomiya, Tochigi, 3210974, Japan (E-mail: kenichihszm@mac.com).

J Thorac Cardiovasc Surg 2011;142:1272-3

$0022-5223 / \$ 36.00$

Copyright (C) 2011 by The American Association for Thoracic Surgery

doi:10.1016/j.jtcvs.2011.05.025
} 


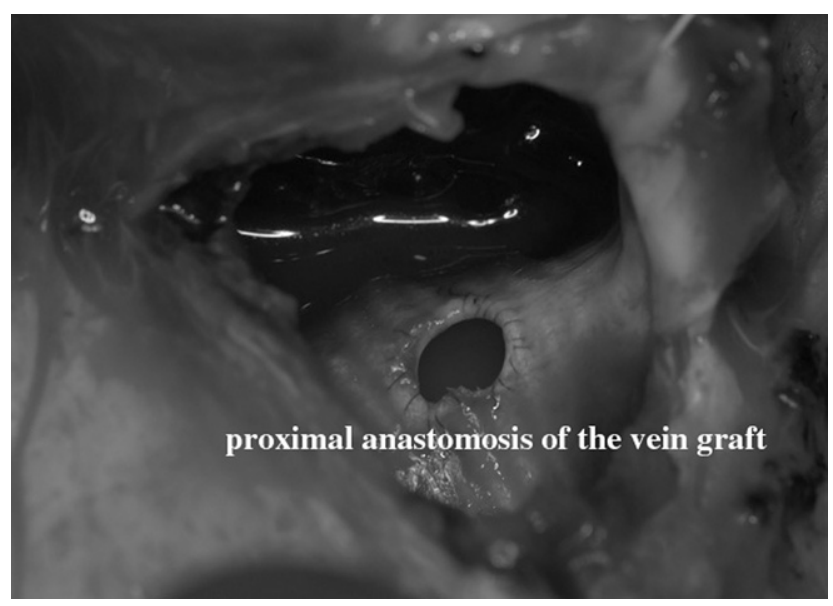

FIGURE 3. When the pseudoaneurysm was opened, it was found that the proximal end of the vein graft had completely detached from the artificial aorta. 